\title{
The Structure Comparison of Necessity Entrepreneurial Resource Support Networks Based on SNA
}

\author{
Yong Tang ${ }^{1}$ \\ ${ }^{1}$ Urban Management Department, Hunan City University, Yiyang, China \\ Correspondence: Yong Tang, Urban Management Department, Hunan City University, Yiyang, P. R. China. Tel: \\ 86-731-635-3164. E-mail: tyzyhtt@126.com
}

Received: August 23, 2013

Accepted: September 11, 2013

Online Published: September 12, 2013

doi:10.5430/bmr.v2n3p137

URL: http://dx.doi.org/10.5430/bmr.v2n3p137

\begin{abstract}
Entrepreneurship is a process of collecting various resources to fulfill its new venture objectives. For necessity entrepreneurs in China, they more urgently need to get support from other agents through networked resource communication. In order to explore the resource network structure, this paper takes an entrepreneurial geographical agglomeration in Cangshupu of Hunan Province in China as a case, and chooses the actors who have the attributes of necessity entrepreneurship based on their Lunar New Year Greeting networks, and then constructs 3 different support networks (material support network, information support network and business exchange network respectively). After comparison analysis using Social Network Analysis, the results show that: 3 networks are generally in low density and long distance, and the density of material network is the sparsest because most contacts only happen among family members or localities; as for clique analysis, the number of cliques in material support network is much less than that in information support network and business support network; as for block analysis, there lacks a block with strong primary position to provide constant material in material support network, while information support network has a block that is taking the role of primary because information network is based on communications of time-honored and newly established actors, and business support network follows the rule of business processes so the simplified network is presented as a star symbol. We also give implication analysis and policy recommendation.
\end{abstract}

Keywords: Necessity Entrepreneurship, Support Network, New Year Greeting Network, Social Network Analysis

\section{Introduction}

For insufficient employment volume and unsatisfactory employment environment, some agents will choose entrepreneurship to support their livelihood instead of taking employment in established firms, and this kind of entrepreneurial motivation is for personal survival and for life necessities, so related expected returns are low when comparing with some other entrepreneurships which are pursuing business opportunity and striving for independence (Jiang Yanfu et al.,2003; Autio, 2005). Necessity entrepreneurship is commonly spread in some emerging economies. According to Jiang Yanfu et al. (2003), 96\% of entrepreneurial activities belong to necessity type in China. Traditional self-employment and most of female entrepreneurship are necessity-driven in the process of China's urbanization (Lucas Hernandez et al., 2012).

Entrepreneurship is a process of maneuvering diversified resources, which are generally not owned by the entrepreneurs (Alvarez, 2001). Meanwhile, entrepreneurship is tightly embedded in specific contexts, specifically within personal and institutional networks (Zahra, 2007; Meek et al., 2010). For weak resource supply and insufficient risk-taking abilities, necessity entrepreneurs have to seek for cheaper resource supplements channels and more reliable evidence to make the decisions, so the resources are more characterized by context-based and network-based. (Boris Urban, 2011; Robert C. Kloosterman, 2010). Network has the abilities to facilitate the entrepreneurs to get resources, and networking allows entrepreneurs to enlarge their business opportunities, to access to critical resources, and to deal with business obstacles (Adler et al., 2002), therefore whether the entrepreneur has enough networks or has the ability to construct resource networks is often considered as another significant source of advantage (Audretsch et al., 2004).

But why some networks can supply resources more efficiently than others? Why some actors in the network can touch the outside resources more easily than other actors? Researchers began to seek answers from the characteristics 
and mechanism of ties among the actors in network, and find that tie strength, tie quantity, as well as the structure of network can contribute to resource acquirement (Luo Jar-Der, 2010; Granovetter,1985; Burt,1992). Though tie is simply the reflection of contact between actors, it is actually a carrier to collect resources, a channel to absorb or disseminate resources or norms. As for weak ties, they are efficient in obtaining information that would otherwise be unavailable or costly to locate, so they can extend one's network boundary by linking more individuals or organizations together and providing an interface for exchanges to take place, and makes him more convenient to touch heterogeneous resources. However, strong ties, which are often formed by sibling or parents, can help out for free in some aspect of the start-up activities, and it is beneficial to provide secure and consistent access to resources. When the research is focused on the strength of network tie, we call it as the relational dimension study (Granovetter, 1985). From another hand, in the whole network, some actors have more ties than others, leading the actors to hold some special roles and positions in the network, and this is called as structural dimension (Burt, 1992).

In necessity entrepreneurship research, some researcher found that strong-tie network is very essential for the start of new business (Ma, 2002). Based on family-tie or emotional cognition, the new entrepreneurs can obtain support resources and establish administration norms from family members or friends, so they can cut down time and energy consuming in accumulating necessary resources and avoid the hardship to explore new business model. While few studies have told us what the necessity support network look like, what characteristics the network has in terms of its structure, especially under the context of China's urbanization. Though necessity entrepreneurship is widely seen in this country, we hardly care about how these entrepreneurs get entrepreneurial resources, though we know most of them have insufficient self-supply abilities. Research on it is not only beneficial for entrepreneurs to know their networking motivation and forms, but also helpful for researcher to understand the mechanism of support network on entrepreneurial effects.

In social science research, Van del Poel (1993) thinks social support is traditionally seen as material (such as money or loan) support, information support (such as technical guidance and market information) and business support (such as buy or sale ties). In order to delineate the features of necessity network, we choose 3 resources above to form 3 kinds of support networks.

\section{Theoretical underpinnings}

In recent entrepreneurial study, structural perspective of network has dominated a great on how to describe the network structure and how different structure affects entrepreneurship (Walker, 1997; Chen et al., 2009). Burt's (1995) structural holes position emphasized both an appeal to the broker opportunities of a network full of disconnected contacts and an appeal to the advantages of the network position. Nann et al. (2010) found universities which are more central in the German university network provide a better environment for students to found more and more successful startups. The more links founders have with alumni of their university, the more successful their startup is, the higher their betweenness in the online network of university alumni, the more successful they are. Greve et al. (2003) made the comparison of several network structures in some countries, and found that family members are most present in networks at the whole process of entrepreneurship, and networking patterns are the same in all countries, but different in size and time spent.

As for how to measure the network structure, social network provides a powerful model for this analysis. Scott (1988) made a review of the formal models proposed in graph theory, multidimensional scaling, and algebraic topology is followed by extended illustrations of social network analysis in the study of community structure and interlocking directorships. It helps us not only delineate the individual actors in the networks but also to determine network ties, density, distance. Density of a binary network is the total number of ties divided by the total number of possible ties, and the distance between two actors is the length of the shortest path. Delineation of the network allows us to see each actor's position in the network and to analyze each actor's role and function in the network. We often use cliques, overlapping membership and blocks to delineate the whole network structure features. Here clique is a maximally complete subgraph, and every actor in clique is fully connected. According to SNA, we can calculate the overlapping membership representing as the number of times each pair of actors is in the same clique. In order to find out the whole network mode, we need to implement transformation in light with the actors' equivalence, and the equivalent actors form a block (Lorreian et al., 1971). For its significance in social studies, all the variables can be presented in mathematical and graphical forms.

\section{Date and methodology}

We mainly take case study in exploring the necessity entrepreneurial resource support network, so the collection of date follows next 3 steps: (1) to find an necessity entrepreneurial agglomeration, and define a whole network, in which every actor is ensured to take necessity entrepreneurship; (2) to collect the resource support date based on new 
year greeting acitvities; (3) to generate the tie matrix based on name generator method.

\subsection{The whole network boundary}

As suggested by Luo Jar-Der (2010), we take an entrepreneurial agglomeration as the boundary. The reason is that necessity entrepreneurship is very probable to happen in geographical proximity for its weak cost and information ability. Yiyang Plastic Packaging Entrepreneurial Agglomeration is located in Yiyang, Hunan Province. Limited by poor natural resources and human resources, industry there is mainly featured as self-development and in running for better livelihood, and most of the entrepreneurships are in the form of household. In order to measure the network structure, we take this Entrepreneurial Agglomeration as the network boundary. We choose 67 actors following necessity entrepreneurship characteristics: (1) entrepreneurial motivation and income is mainly for livelihood; (2) business is mainly operated by owners; (3) the business has small scale, and related yearly net profit is less than 250000 yuan. Based on their business types and business history, we categorized them into 6 sections:

Table 1. The sections of samples

\begin{tabular}{|c|c|c|}
\hline Section & Actors & Features \\
\hline Section 1 & actor1-actor 24 & For plastic package production \\
\hline Section 2 & actor 25 -actor 35 & For plastic package sales \\
\hline Section 3 & actor 36-actor41 & For equipment maintenance and sales \\
\hline Section 4 & actor 42 -actor 46 & All are time-honored businesses (more than 20 years) \\
\hline Section 5 & actor 47 -actor 52 & All are newly entrants (less than 2 years) \\
\hline Section 6 & actor 53 -actor 67 & For non-package businesses \\
\hline
\end{tabular}

\subsection{The date collection}

We collect support network matrix date through on-site investigation and questionnaire from May-July, 2012. In China, Lunar New Year greeting is a very formal while effective means in showing the relations. So, as for the 64 actors, we firstly ask every actor to fill in the names with whom he has made formal New Year greeting this year; then, ask every actor to tell what kind of resources the greeted actor has given to him. The questionnaire is as below:

Table 2. The questionnaire of support network

Basic information

\begin{tabular}{|c|c|c|c|}
\hline Your name & & Business scale (sales volume) & \\
\hline Main business type & & Locality or migrant? & \\
\hline Business start time & & The totality of new year greeting & \\
\hline
\end{tabular}

Underline the code that your have made New Year greeting with this year

\begin{tabular}{|c|c|}
\hline Code & Business name \\
\hline 1 & Yiyang Hongyuan plastic processing company \\
\hline 2 & Yiyang Guanzi packing company \\
\hline 3 & Yiang Nanfang plastic business company \\
\hline$\ldots$ & \\
\hline 67 & Zhongyuan leisure center \\
\hline
\end{tabular}

As for the underlined companies above, please choose in detail the support relations

\begin{tabular}{|c|c|c|c|c|}
\hline $\begin{array}{c}\text { Contact } \\
\text { Name+Code }\end{array}$ & $\begin{array}{c}\text { Contact time } \\
\text { (year) }\end{array}$ & Material support & Information support & Business support \\
\cline { 3 - 5 } & & Yes: 1 No: 0 & Yes: 1 No: 0 & Yes: 1 No: 0 \\
\hline & & & & \\
\hline & & & & \\
\hline & & & & \\
\hline
\end{tabular}

\section{3 methodologies}

We follow the processes recommended by Everett (2002) to measure the structure of network: firstly, we basically calculate some whole variables; then we proceed clique analysis and overlapping member analysis; and finally we implement block analysis. All processes are operated using social network analysis with the aid of Ucinet 6.0. 


\section{Result}

\subsection{Network measurement}

Because all networks are based on actor's New Year greeting networks, they have same actors (same network scale). We construct 3 binary matrixes in light with 3 different resource, and they are graphically presented by Ucinet as figure 1, 2, 3 (material support network, information support network and business exchange network. Related network statistics are presented in table 3 .

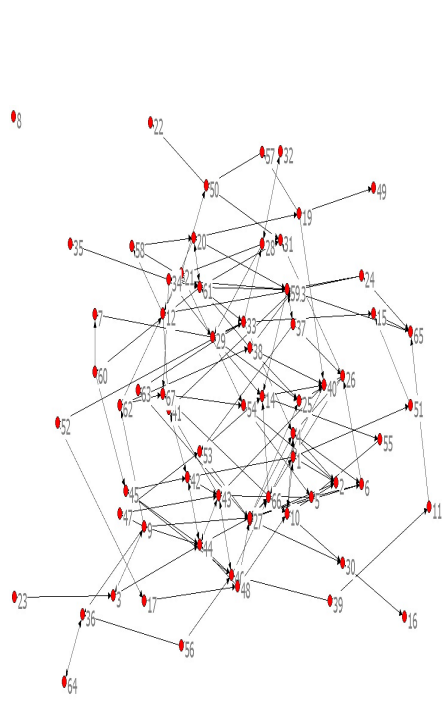

Figure 1. Material support network

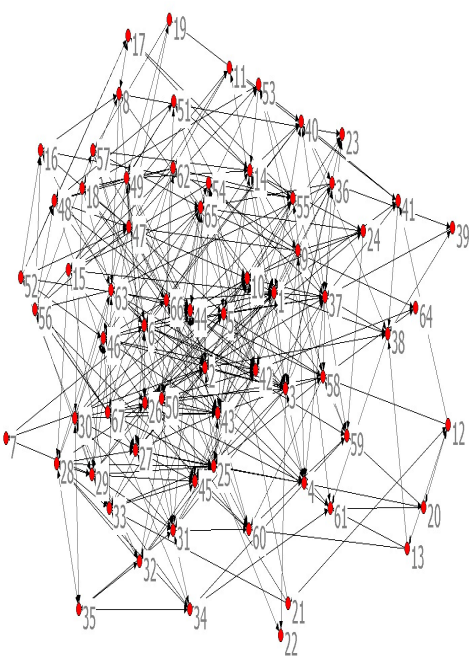

Figure 2. Information support network

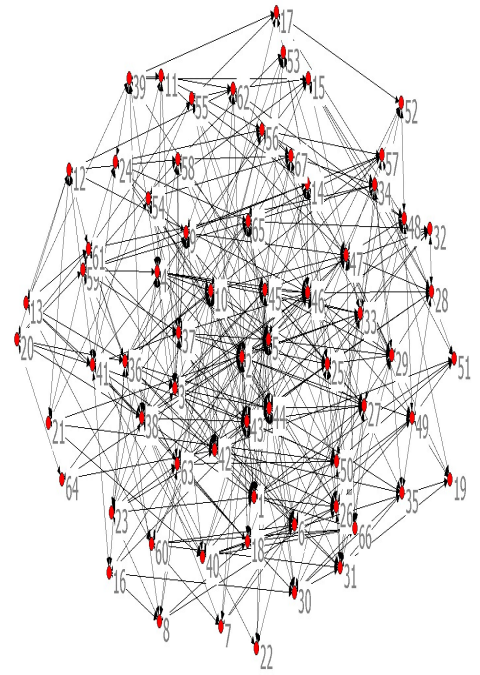

Figure 3. Business exchange network

Table 3. Overall structure statistics of 3 networks

\begin{tabular}{|l|l|l|l|l|}
\hline \multirow{2}{*}{$\begin{array}{l}\text { Serial } \\
\text { number }\end{array}$} & \multirow{2}{*}{ Variables } & Network category & \multicolumn{3}{|l|}{} \\
\cline { 3 - 5 } & & Material support & Information support & Business support \\
\hline 1 & Density & 0.0369 & 0.1065 & 0.1714 \\
\hline 2 & Density deviation & 0.1884 & 0.3085 & 0.3769 \\
\hline 3 & Average distance cohesion & 4.832 & 2.576 & 1.985 \\
\hline 4 & $\begin{array}{l}\text { Distance-based } \\
\text { ("Compactness") }\end{array}$ & 0.181 & 0.450 & 0.560 \\
\hline 5 & $\begin{array}{l}\text { Distance-weighted } \\
\text { fragmentation ("Breadth") }\end{array}$ & 0.819 & 0.550 & 0.440 \\
\hline
\end{tabular}

Table 4. Network degree centrality measures

\begin{tabular}{|l|l|l|l|l|l|l|}
\hline \multirow{2}{*}{ Serial Number } & Material support network & Information support network & \multicolumn{2}{l|}{ Business exchange network } \\
\cline { 2 - 7 } & OutDegree & InDegree & OutDegree & InDegree & OutDegree & InDegree \\
\hline mean & 2.433 & 2.433 & 7.030 & 7.030 & 11.313 & 11.313 \\
\hline Std Dev & 1.468 & 1.747 & 4.070 & 4.340 & 4.915 & 4.915 \\
\hline Sum & 163 & 163 & 471 & 471 & 758 & 758 \\
\hline Minimum & 0 & 0 & 0 & 1 & 4 & 4 \\
\hline Maximum & 6 & 7 & 19 & 19 & 25 & 25 \\
\hline centrality & $5.47 \%$ & $7.03 \%$ & $18.41 \%$ & $18.41 \%$ & $21.05 \%$ & $21.05 \%$ \\
\hline
\end{tabular}


Table 5. Network degree measures

\begin{tabular}{|l|l|l|l|l|l|l|l|l|l|l|l|l|}
\hline \multirow{2}{*}{ NO. } & \multicolumn{3}{|l|}{ Material support network } & \multicolumn{3}{l|}{ Information support network } & \multicolumn{3}{l|}{ Business exchange network } \\
\cline { 2 - 13 } & Node & Out & Node & In & Node & Out & Node & In & Node & Out & Node & In \\
\hline 1 & 9 & 6 & 4 & 7 & 1 & 19 & 44 & 19 & 44 & 25 & 44 & 25 \\
\hline 2 & 34 & 5 & 44 & 7 & 25 & 19 & 43 & 18 & 2 & 24 & 2 & 24 \\
\hline 3 & 1 & 5 & 43 & 6 & 2 & 16 & 42 & 16 & 43 & 22 & 43 & 22 \\
\hline 4 & 43 & 5 & 14 & 6 & 3 & 16 & 10 & 15 & 42 & 21 & 42 & 21 \\
\hline 5 & 19 & 4 & 2 & 5 & 5 & 15 & 1 & 14 & 46 & 21 & 46 & 21 \\
\hline 6 & 20 & 4 & 42 & 5 & 37 & 13 & 5 & 14 & 45 & 18 & 45 & 18 \\
\hline 7 & 44 & 4 & 10 & 5 & 47 & 12 & 26 & 13 & 5 & 18 & 5 & 18 \\
\hline 8 & 2 & 4 & 59 & 5 & 26 & 12 & 27 & 13 & 38 & 18 & 38 & 18 \\
\hline 9 & 38 & 4 & 61 & 5 & 29 & 12 & 25 & 12 & 3 & 17 & 3 & 17 \\
\hline 10 & 26 & 4 & 45 & 4 & 6 & 11 & 2 & 12 & 47 & 17 & 47 & 17 \\
\hline 11 & 27 & 4 & 41 & 4 & 66 & 11 & 3 & 12 & 10 & 17 & 10 & 17 \\
\hline 12 & 18 & 4 & 40 & 4 & 10 & 11 & 46 & 12 & 1 & 17 & 1 & 17 \\
\hline
\end{tabular}

The figures and statistics show that, on average, every network is at low density and long average distance comparing with other opportunity entrepreneurial networks (for opportunity entrepreneurial network, the density is over 0.2, and average distance is less than 2.2, see Jiang Yanfu et al., 2003), reflecting the insufficiency in actors' communication though the actors have some requirement on supplementary resources. Among 3 networks, the material support network is the sparsest, demonstrating that the actors are more careful in supplying and absorbing materials to and from other actors than that in other networks. We can find that in business support network, all ties are two-directed, proving that the trust can easily constructed along with business exchange. We then eliminate actor 42-46 (the time-honored actors), and find that material network keeps almost unchangeable because most actors who have material support behavior are relatives or family members. The result testifies the conclusion that material support is always happening with strong ties, also confirms that necessity entrepreneurs cannot find the appropriate partners to contact frequently besides their relatives or family members (Tüzin Baycan-Levent et al., 2009; Anderson, 2008). However, the other 2 networks have very different statistics data; we can easily find the "centers" of these two networks (such as node 44, 42, 43), so information and business support are mainly maintained by entrepreneurial pioneers. Table 4 delineates the centrality of 3 networks, it reaffirms that in material support network, family-tie is more randomly emerged, and thus centrality is much lower than that of others. Table 5 is the collection of high degree actors in 3 networks. Information support network and business exchange network have similar high degree nodes (most of the time honored actors have high degrees), but in material support network, the high degree actors are up to the scale of clans or family member.

\subsection{Cliques}

A clique is a sub-set of a network in which the actors are more closely and intensely tied to one another than they are to other members of the network. Some scholars have designed algorithm on calculating clique (or cluster) in networks. In social network analysis, a clique is the maximum number of actors who have all possible ties present among themselves. According to SNA, the actors repeatedly appear in different cliques have the positions of bridge for other actors or core for the network cohesion. For their special roles, they can always facilitate resource flow among the network. From the whole perspective, more overlapping membership can strengthen the information sharing possibility and lower the information collection cost. We choose minimum size of 3 to calculate the cliques, and get 23 cliques in material support network, 169 cliques in information support network and 209 cliques in business support network. If we increase the minimum size to 4 , for material support network we can only find 1 clique, while for other two networks, related clique number is 61 and 79 (figure 4, 5 and 6). The result indicates that cliques in material support network, which is always based on strong ties, cannot easily be nurtured beyond the predestinated relations. The great majority of actors will refer to relatives even they have more relations with other actors. So, we can also find that the entrepreneurs cannot solve loan problems if their have no rich relatives unless some agencies (such as government) initiatively issue material support resources. However, other two networks have significantly more cliques and co-members (the top line number in every figure shows every actor's co-membership), 
and most cliques are based on the relation among time-honored actors and others in information support network, based on business processes in business support network. Obviously, the communication in these two networks is not so conservative, and the phenomena of knowledge spillover are widely seen. An actor who has more co-membership means he is more probable to connect different cliques, to strengthen the communication of information and technology. As for the preference of communication, actors are more willing to communicate in the form of information or business, but less in material (such as money lending, loans, etc.).

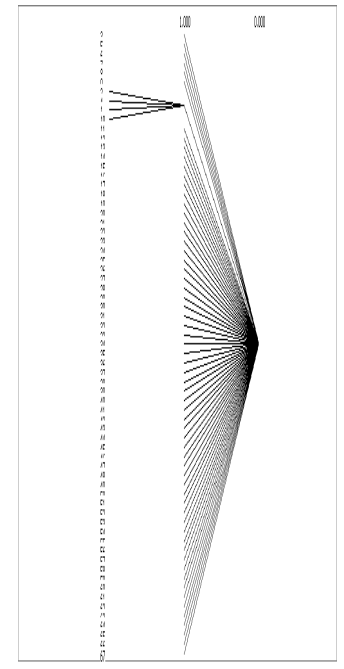

Figure 4. Material support network cliques and overlapping membership

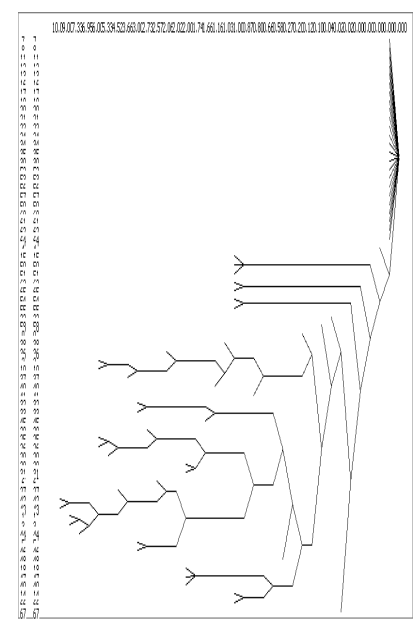

Figure 5. Information support network cliques and overlapping membership

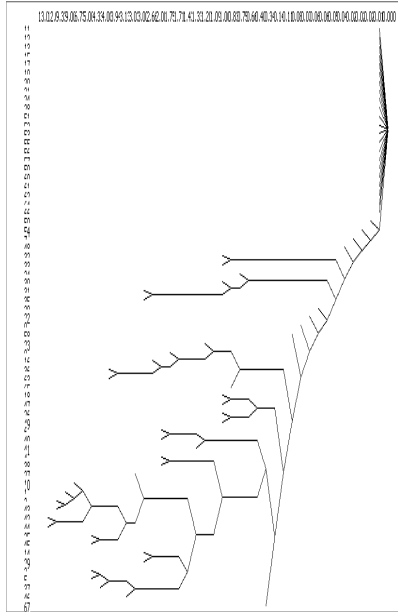

Figure 6. Business exchange network cliques and overlapping membership

\subsection{Block analysis}

We use Concor algorithm to calculate the blocks in order to divide the whole network into some separated fractions and find out the equivalent actors in the whole network. We firstly calculate the clusters and blocked matrix for 3 networks (see clique diagrams in figure 4, 5 and 6), then we build binary matrix according to cluster density and network average density, and at last draw the simplified network in light with binary matrix seen as in figure 5, 6 and 7.. In each figure, the left box is the actors in each block, and the right box is the simplified network which shows the structural equivalent of actors.
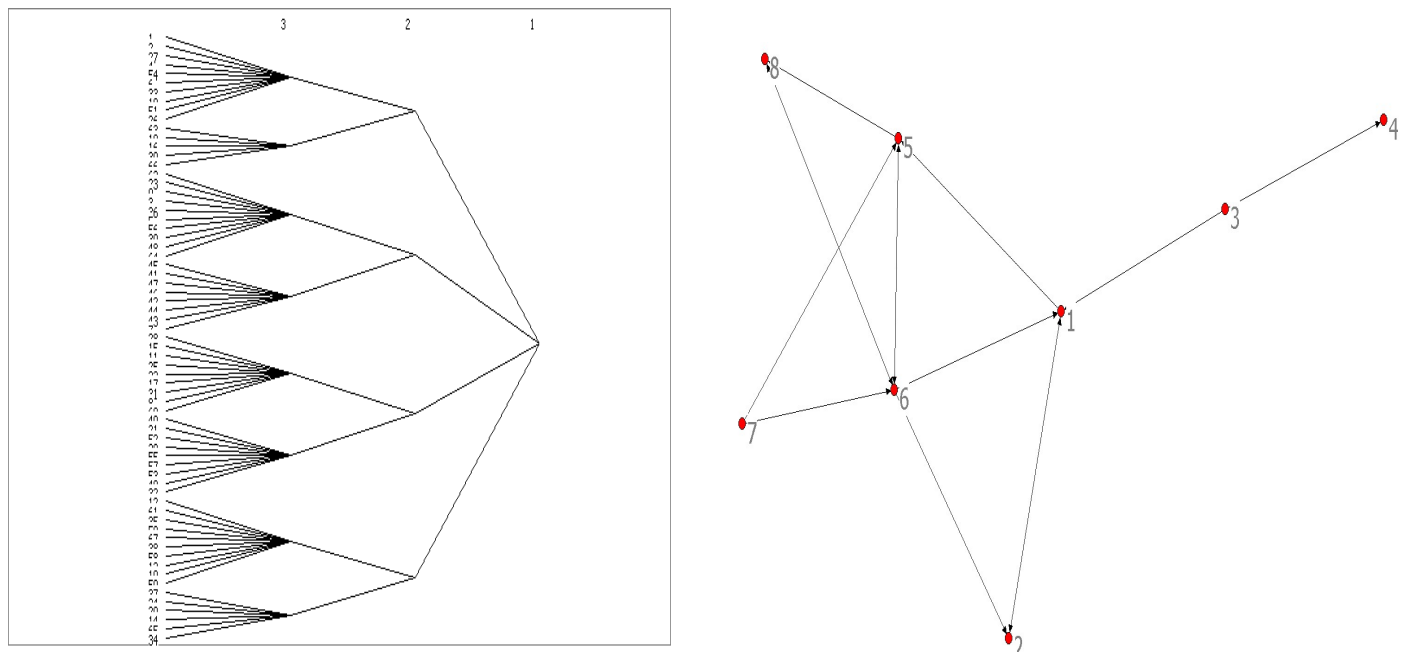

Figure 7. Material support network blocks and simplified network 

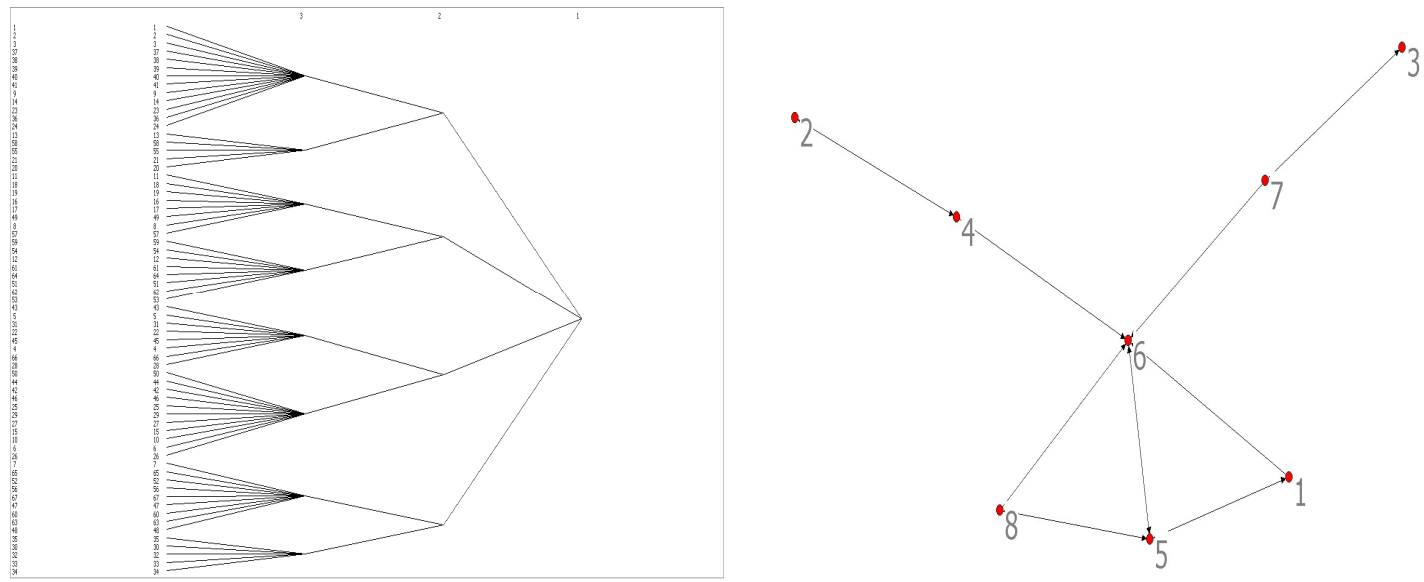

Figure 8. Information support network blocks and simplified network
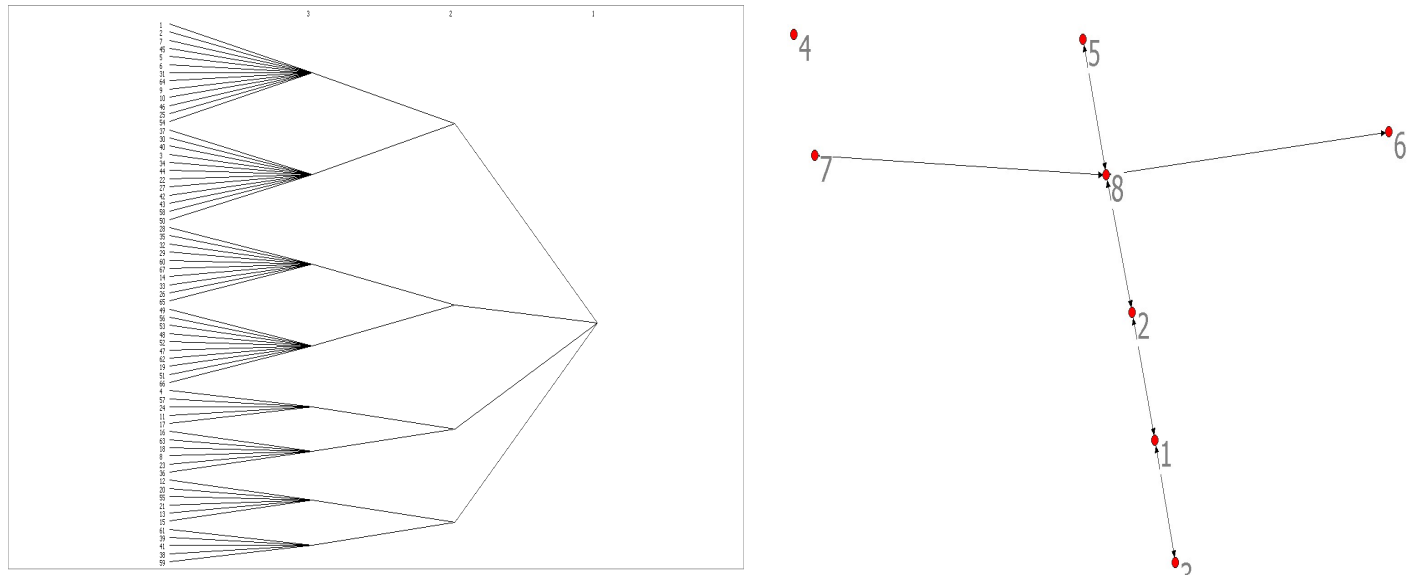

Figure 9. Business exchange network blocks and simplified network

From the simplified network, we can see that as for material support, the whole network is mapped out as an equivalent hierarchical situation, each block is comprised of actors who have strong ties, and most of blocks are generally structurally equivalent because they have the same relationships to all other blocks, so most of the blocks have the broker-like positions. However, the other 2 networks are much simpler in terms of their positions. Taking business support network as an example, the block 4 is an isolated one, indicating the actors in this block only need to communicate within the block; block 8 has bigger in degree than out degree, signifying actors there are mostly business receivers; block 5,6 and 7 have only one degree, so the actors in these blocks will only communicate with actors in block 8. From simplified networks, we can find that in business and information support networks, actors can comparatively freely choose the actors as they want to communicate, so the networks are more regular in their structure. While in material support network, most of the communications are predestinated by the strong ties, so the whole network structure will be more complicated in figuration.

\section{Conclusion and Discussion}

In order to get insight into the structure of necessity support network structure, we take an entrepreneurial geographical agglomeration as a case, and choose the actors who have the attributes of necessity entrepreneurship based on their Lunar New Year Greeting network, and then to form 3 different support networks (material support network, information support network and business exchange network), so as to make the comparison analysis of necessity entrepreneurial support network structure using SNA.

From overall structures statistics, we know that 3 networks are in low density comparing with other entrepreneurial networks, indicating actors are not active in contacting with others, especially in building weak ties to get diversified social resource support. The reason maybe twofold: first, necessity entrepreneurship is mostly exploitative, so the 
knowledge structure is not very complicated; then, the actors have less ability in expanding their network scope and density. The density of material network is the sparsest because most of contacts happen in family members or localities, and the tie is strictly constrained into small scale.

From clique analysis, we know that the amount of cliques varies significantly from one network to another. The number of cliques in material support network is much less than that in information support network and business support network. So, material network actually is more seriously confined, and the communication is even more complicated.

From blocks analysis, we find that there lacks a block with strong primary position to provide constant material in material support network, while information support network has a block that is taking the role of primary, so others can possibly get information from this block without too much barrier. In business support network, the actors basically follow the rule of business processes, so the simplified network is presented as a star symbol.

This study has some possible implications. Our research find that material constraint is the biggest problem in necessity entrepreneurship, so the policy makers should add more actors who have abilities in releasing more materials (such as more loaners). We also find that information support network is mainly connected by time-honored and the newly established actors, and business support network is mainly motivated by business processes. Though the ties and structure analysis show that these two kinds of networks are more effective in supporting entrepreneurship, we still believe that in order to maintain the sustainability, the networks should introduce more heterogeneous resources, and the policy makers should set more roles (or network cores) in network, and encourage the actors communicate more actively and freely, from both vertical and horizontal dimensions.

There are several limitations to our study. First, as most researches using SNA, we only take case study to explore and testify the result, so the external validity will be affected due to small sample size and particular context of the entrepreneurship. Second, our aim is only to explore the network structure, so the relation between network structure and detailed performance of every entrepreneurial actor is not clear. Further study can be implemented with consideration of both network structure and actors' performance.

\section{Acknowledgements}

The research is financed by National Social Science Foundation of China (Grant No. 13CGL022) Hunan Provincial Social Science Foundation of China (No. YBA045), Hunan Provincial Natural Science Foundation of China (No.12JJ6071). It is also financed by Hunan City Economy Base and Hunan Urbanization Research Base.

\section{References}

Adler, P. S., Kwon, S. W (2002). Social capital: prospects for a new concept. Academy of Management Review, 27(1) 17-40. doi: 10.5465/AMR.2002.5922314

Alistair R. Anderson, Edward Yiu-chung Lee (2008). From tradition to modern: attitudes and applications of guanxi in Chinese entrepreneurship. Journal of Small Business and Enterprise Development, 15(4),775-787. doi:10.1108/14626000810917852

Alvarez S A, Busenitz L W (2001). The entrepreneurship of resource-based theory. Journal of Management. 27(6) 755-775. doi: 10.1177/014920630102700609

Audretsch, D., Keilbach, M (2004). Entrepreneurship capital and economic performance. Regional Studies, 38(8) 949-959. http://www.tandfonline.com/doi/abs/10.1080/0034340042000280956

Autio, E (2005). Report on High-expectancy Entrepreneurship, Global Entrepreneurship Monitor Report. Babson College and London Business School, 2005.

Burt, R. S (2009). Structural holes: The social structure of competition. Harvard University Press.

Chen, W., Tan, J (2009). Understanding transnational entrepreneurship through a network lens: Theoretical and methodological considerations. Entrepreneurship Theory and Practice, 33(5) ,1079-1091. doi:10.1111/j.1540-6520.2009.00335.x

Evertt, M (2002). Social Network Analysis. Essex: Textbook at Essex Summer School in SSDA.

Granovetter, M (1985). Economic action and social structure: the problem of embeddedness. American Journal of Sociology, 481-510. http://www.jstor.org/discover/10.2307/2780199?uid=3737800\&uid=2\&uid=4\&sid=21102575952933

Greve A, Salaff J W (2003). Social networks and entrepreneurship. Entrepreneurship Theory and Practice, 28(1), 
1-22. doi: 10.1111/1540-8520.00029

Jiang Yanfu et al. (2003). Global Entrepreneurship Monitor China 2002. Tsinghua University Press, China, 2003. (in Chinese)

Lorrain, F., White, H. C (1971). Structural equivalence of individuals in social networks. The Journal of mathematical sociology, 1(1),49-80. http://www.tandfonline.com/doi/abs/10.1080/0022250X.1971.9989788

Lucas Hernandez, Nicholas Nunn, Tonia Warnecke (2012). Female entrepreneurship in China: opportunity or necessity-based?. International Journal of Entrepreneurship and Small Business, 15(4) 411-434.doi:http://dx.doi.org/10.1504/IJESB.2012.046473

Luo Jar-Der (2010). Social Network analysis. Social science Academic Press, China, 2010 (second edition), in Chinese.

Ma, Z (2002). Social-capital mobilization and income returns to entrepreneurship: the case of return migration in rural China. Environment and Planning A, 34(10),1763-1784. http://citeseerx.ist.psu.edu/viewdoc/download?doi:10.1.1.197.9231\&rep=rep1\&type=pdf

Meek W R, Pacheco D F, York J G (2010). The impact of social norms on entrepreneurial action: Evidence from the environmental entrepreneurship context. Journal of Business Venturing, 25(5) 493-509. http://dx.doi.org/10.1016/j.jbusvent.2009.09.007

Nann, S., Krauss, J., Schober, M., Gloor, P., Fischbach, K., \& Führes, H (2010). The power of alumni networks-success of startup companies correlates with online social network structure of its founders. (January 11, 2010). MIT Sloan Research Paper No. 4766-10. http://dx.doi.org/10.2139/ssrn.1534699

Robert C. Kloosterman (2010). Matching opportunities with pesources: A Framework for analysing (migrant) entrepreneurship from a mixed embeddedness perspective. Entrepreneurship \& Regional Development: An International Journal, 22(1) 25-45. http://www.tandfonline.com/doi/abs/10.1080/08985620903220488

Scott J (1988). Social network analysis. Sociology, 22(1) ,109-127. doi: 10.1177/0038038588022001007

Tüzin Baycan-Levent, Peter Nijkamp (2009). Characteristics of migrant entrepreneurship in Europe. Entrepreneurship \& Regional Development: An International Journal, 21(4),375-397. http://www.tandfonline.com/doi/abs/10.1080/08985620903020060

Urban, Boris (2011). Social capital configurations for necessity-driven versus opportunity-driven entrepreneurs. South African Journal of Economic and Management Sciences,14(4),407-421. http://www.scielo.org.za/scielo.php?pid=S2222-34362011000400004\&script=sci_arttext

Walker, G., Kogut, B., Shan, W (1997). Social capital, structural holes and the formation of an industry network. Organization Science, 8(2) ,109-125. doi: 10.1287/orsc.8.2.109

Van der Poel, M. G (1993). Delineating personal support networks. Social Networks, 15(1), 49-70. http://dx.doi.org/10.1016/0378-8733(93)90021-C

Zahra S A (2007). Contextualizing theory building in entrepreneurship research. Journal of Business Venturing, 22(3) 443-452.http://dx.doi.org/10.1016/j.jbusvent.2006.04.007 